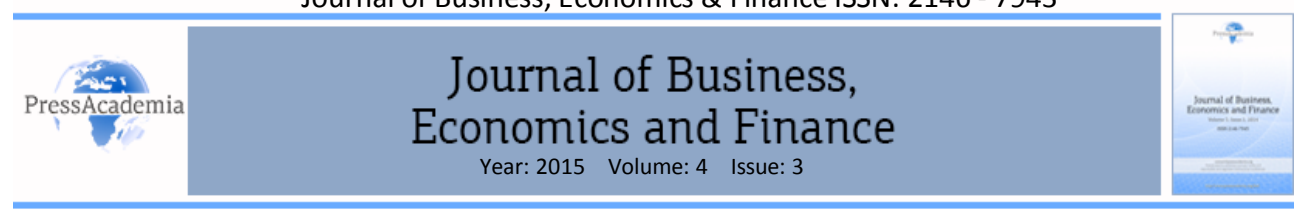

\title{
THE HEDGING EFFECTIVENESS AND THE STABILITY OF THE OPTIMAL HEDGE RATIOS: EVIDENCE FOR THE ISTANBUL STOCK EXCHANGE 30 CONTRACT
}

\section{DOI: $10.17261 /$ Pressacademia.2015313057}

\author{
Hakan Er', Aysegul Ates ${ }^{2}$ \\ ${ }^{1} A k d e n i z$ University, Turkey. Email: erhakan@akdeniz.edu.tr \\ ${ }^{2}$ Akdeniz University, Turkey. Email: aates@akdeniz.edu.tr
}

Keywords
Futures,
Hedging
Effectives,
Beta Stability,
Istanbul Stock
Exchange,
TurkDEX

JEL Classification G11, G13, G14, G15, G32

\begin{abstract}
In this paper we investigate ex ante hedging effectiveness of the Istanbul Stock Exchange 30 (ISE 30) stock index futures contract covering the period January 2007-December 2014. An optimal hedge ratio is typically calculated by regressing historical spot prices, spot price changes or spot returns on futures prices, futures price changes or returns. The slope of the regression is then used as the optimal hedge ratio. However, no guidelines are provided on what return interval and estimation period should be chosen for the calculation of returns. The empirical research has shown that hedge ratio estimates are not invariant to the return measurement interval or the estimation period. This study finds that although the daily returns for the estimation of hedge ratio provides the best ex-post performance, ex-ante tests favor hedge ratios calculated with longer return intervals and estimation periods. While one should expect greater precision for longer estimation periods, results of this study do not provide satisfactory evidence in favor of this argument.
\end{abstract}

\section{INTRODUCTION}

Stock index derivatives have gained phenomenal success within a short space of time. Low transaction costs in the derivatives markets are compared favorably with the higher costs in the cash market. Further, the cash market may have illiquidities in the availability of the stocks. Index derivatives, on the other hand, are typically cash settled and hence have no liquidity issues. Moreover, although stock exchanges impose restrictions on short selling of stocks, short positions are easily available in the futures markets. For the reasons stated above, stock index futures are ideal vehicles to hedge equity portfolios against market risk. The potential offered by futures in extending risk management capabilities attracted many investors and it has generated strong academic interest soon after their introduction. As the determination of the correct hedge ratio is of paramount importance for portfolio managers for the hedge construction and its effectiveness, the hedging performance of the futures contracts has become one of the most widely studied issues in research on derivatives. In the mean- mean-variance framework, the optimal hedge ratio, the value that minimizes the variance of the return on the hedged portfolio, is found by dividing covariance between the returns on spot and futures by the variance of the futures return. Finding the optimal hedge ratio is just a matter of finding the best possible time 
series model to describe the return data. Although more recent studies adopt generalized autoregressive conditional heteroscedasticity (GARCH) framework for finding optimal hedge ratios as GARCH techniques handle time varying nature of the financial data well, probably the most widely used method by practitioners for this task is to calculate the hedge ratio by regressing historical spot prices, spot price changes or spot returns on futures prices, futures price changes or returns. A stock index futures contract on an index that is assumed to track market movements well is chosen and the hedge ratio is estimated by the ordinary least squares (OLS) regression model of the rate of returns of the portfolio on those of the futures. The coefficient of the futures return, or its beta is then used as the optimal hedge ratio. However, the choice on the return interval and estimation period is critical for the calculation of returns. Typically, daily returns measured over short time periods are used for the estimation of the hedge ratios. If returns are independent and identically distributed, betas estimated using daily returns should not be substantially different than those estimated by weekly, bi-weekly or monthly returns. Moreover, the choice of the estimation period should not have an effect of a portfolio's beta as long as the structural characteristics of the firms in the portfolio do not change over time. As the empirical research has shown that beta estimates are not invariant to the return measurement interval or the estimation period, it is important to know how the choice on return interval and estimation period affects beta estimates. Although there is a vast financial literature on this subject using developed market data, compared to the number studies on developed markets, the number of studies covering emerging market data is still limited. Especially the number of studies employing Turkish data is scant.

Within this context, we aim to contribute to the financial literature in two ways. First, we provide new empirical evidence on this subject from an important emerging market by analyzing the hedging effectives of Turkish stock index futures on an actual diversified portfolio of Turkish stocks. Second, we utilize a methodology that has never been applied to Turkish data before. The rest of the paper is organized as follows. Section Two provides a brief review of the literature on hedging effectiveness. Data and methodology is presented in Section Three. Section Four summarizes the results of the study. Section Five concludes and provides suggestions for future work.

\section{LITERATURE REVIEW}

The issue of the stability of betas was first studied in the context of Capital Asset Pricing Model (CAPM) research. It is clear that as the number of returns used in a sample increases, the standard error of the estimated beta should decrease. Therefore, lengthening the estimation period should improve the precision of these estimates. Whether or not this improved precision results in increased stability in the estimated betas is an empirical question. Blume (1971) is one of the first studies that investigate the impact of the length of the estimation period on the estimation of the betas. The results of the study show that portfolio betas are highly stable for longer-terms. Individual security betas, on the other hand, are not stable. Baesel (1974) and Altman, et al. (1974), both varied the estimation period and concluded that stability of individual beta coefficients increases as the length of the estimation period increases. Roenfeldt (1978) concluded that forecasting betas based on a four-year previous period are more reliable 
for subsequent four-, three-, and two-year periods than for only the next year. The abovementioned studies find that betas are stable if the initial and subsequent estimation periods are of the same length. In practice, however, betas estimated using longer estimation periods are used for shorter subsequent periods. Betas estimated from lengthy samples should be more prone to the effects of the structural changes in firms/firms in the portfolios. Although a lengthy estimation period should provide a more precise beta estimate, estimated betas might fail to reflect many recent structural changes. A large number of empirical studies provide evidence that betas change over time. Fabozzi and Francis (1978) study is one of the first studies that demonstrate that beta coefficients calculated by the OLS regressions move randomly through time. Many other studies studies across a range of stock markets (Sunder, 1980; Bos and Newbold, 1984; Collins, et al. 1987; Faff et al. 1992; Brooks et al. 1992, 1994) provided evidence that betas are not stationary. As the GARCH techniques handle time varying nature of the financial data well, many recent studies employed these techniques to estimate conditional time dependent betas.

CAPM research also revealed that returns measured over short periods of time have more information. However, these returns, especially daily returns, suffer from nonsynchronous trading problem which results in serial correlation in returns (Kim, 1999). One possible remedy to this problem is to increase the return measurement interval. However, serial correlation, although weakened, is still a problem for longer period returns. Moreover, for stocks/portfolios riskier (less risky) than the market estimates of beta increases (decreases) as the return interval increases (Cohen et al., 1985, Handa et al., 1989). With the introduction of stock index futures a vast literature on hedging effectiveness has quickly developed. As the estimation procedure for the optimal hedge ratios are very similar those used for the estimation of CAPM betas, this line of research also considered the issues of the stability of the hedge ratios and the impact of the return interval on the effectiveness of the optimal hedge ratios. Figlewski (1984), Holmes (1996), Howard and D'Antoniou (1987), Lindahl (1992) and Butterwoth and Holmes (2001) are among the many studies on finding methods for calculating optimal hedge ratios and analyzing the performance of the alternative methods.

Most of the studies on hedging effectiveness concluded that hedge ratios estimated by GARCH techniques should be preferred to OLS based ratios. However, most of the time the improvement provided by the unconditional variances are usually minimal (Lien, 1996, 2004; Moosa, 2003; Bowman, 2004). Majority of the studies on hedging effectives focus on developed markets. Research on emerging markets is relatively limited. Sim and Zurbruegg (2001) study on South Korean index futures, Floros and Vougas (2006) study on Greek stock index futures, Bhaduri and Durai (2008) on Indian stock index futures and Kavussanos and Visvikis (2008) stdy on Greek stock index futures are examples of studies that use emerging market data. Although Turkish Derivatives Market has now become one of the most successful derivatives markets, to our best knowledge, there are only two studies on hedging effectiveness of Turkish futures (Çinko and Avcl, 2010, and Olgun and Yetkiner, 2011). There is also another study by Er and Hushmat (2012), however, their focus is not directly on testing the hedging effectiveness of the futures. They use a CAPM 
based hedge ratio and the cost-of-carry relation to test performance of technical rules generated from spot prices and then applied on futures contracts.

The review of the literature shows that majority studies on hedging effectiveness are on developed market data. Moreover, most of these studies employ GARCH techniques to estimate the hedge ratios. To our best knowledge, there is no study on the ex-ante hedging performance of the Turkish stock index futures analyzing the effectiveness of OLS based hedge ratios estimated from samples of varying size and returns calculated over different intervals. This is what this paper seeks to contribute the literature.

\section{DATA AND METHODOLOGY}

In this paper, empirical analysis is based on daily, weekly, bi-weekly and monthly returns from January 2007 to December 31, 2014 on an equally weighted portfolio constructed from the following 15 Istanbul Stock Exchange (ISE) stocks: Adana Çimento, Akbank, Alarko Holding, Anadolu Sigorta, Aygaz, Ereğli Demir Çelik, Keretivaş, Frigo Pak Gıda, İzmir Demir Çelik, Migros, Martı Otel İşletmeleri, Turkish Airlines, Turkcell, Pınar Süt and Zorlu Energy. All stocks continuously traded on the market during the sample period. In order to construct a well-diversified portfolio, we included stocks from almost all sectors. Most of these stocks are high capitalization and low risk stocks. Their products and services are well known by the Turkish public. The consideration here is to minimize the effects of thin trading.

Initial portfolio value is set to TRY $1,500,000$. As the portfolio is equally weighted, initial investment on each stock is TRY 100,000 . The number of each stock to be bought, $N_{i}$, is then calculated by dividing TRY 100,000 by the closing price of the stock on the first trading day of January 2007. Closing prices were obtained from Istanbul Stock Exchange. Starting from the second trading day of January 2007, the portfolio value is recalculated by summing the product of each stocks new closing price, $\mathrm{P}_{\mathrm{it}}$, and $\mathrm{N}_{\mathrm{i}}$. In order to maintain equal weights, we change $\mathrm{N}_{\mathrm{i}}^{\prime}$ s only when there is a stock split, bonus shares (stock dividend) or a cash dividend payment. In case of a stock split or stock dividend on share i, the $\mathrm{N}_{\mathrm{i}}$ is multiplied by $(1+$ split or stock dividend ratio). In case of the cash dividend payments, the cash obtained is allocated to the shares equally and all $\mathrm{N}_{\mathrm{i}}$ 's are increased by the amount invested in each share.

ISE-30 futures daily data was also obtained from Istanbul Stock Exchange. Like many of the emerging markets, futures contracts (and other derivatives) are relatively new for Turkey. Turkish Derivatives Market (TurkDEX) was established in 2001 and started to trade in 2005. The futures contracts did not attract market interest during the course of first six months. During this period there were trading days during which no transactions on the contracts took place. However, from November 2005 onwards the trading volume increased dramatically. TurkDEX ranked 30th derivatives exchange with $62,474,464$ 
contracts traded in $2012^{1}$. The contract specifications of the ISE-30 futures are summarized in Table 1:

Table 1: ISE 30 Index Futures Contracts

\begin{tabular}{|l|l|}
\hline \multicolumn{1}{|c|}{ Underlying Asset } & \multicolumn{1}{|c|}{ ISE 30 Index } \\
\hline Contract Size & $\begin{array}{l}\text { Value calculated by dividing the index value by } 1000 \text { and } \\
\text { multplying the quotient by TRY } 100 \text { (ISE } 100 \text { index /1000)*100 }\end{array}$ \\
\hline Minimum Price Tick & Price tick is 0.025 which corresponds to TRY 2.5 \\
\hline Contract Months & $\begin{array}{l}\text { February, April, June, August, December (Contracts with two } \\
\text { different expiration months to nearest to the current month shall } \\
\text { be traded concurently) }\end{array}$ \\
\hline Settlement Method & Cash Settement \\
\hline Expiry date & $\begin{array}{l}\text { Last business day of each contract month. In case domestic } \\
\text { markets are closed for half day due to an official holiday, expiry } \\
\text { date shall be the preceding business day. }\end{array}$ \\
\hline Last Trading Day & $\begin{array}{l}\text { Last business day of each contract month. In case domestic } \\
\text { markets are closed for half day due to an official holiday, expiry } \\
\text { date shall be the preceding business day. }\end{array}$ \\
\hline
\end{tabular}

The continuous futures price series is created from the nearest contract from five business days from its inception until five business day before its maturity.

Portfolio and futures returns are calculated using the following formula:

$R_{t}=\frac{P_{t}-P_{t-1}}{P_{t-1}}$

$R_{f t}=\frac{F_{t}-F_{t-1}}{F_{t-1}}$

Where $R_{t}$ is the return on portfolio for period $t, P_{t}$ and $P_{t-1}$ are the portfolio values on the periods $t$ and $t-1$. $F_{t}$ and $F_{t-1}$ are the futures prices on the periods $t$ and $t-1$, respectively, and $R_{f t}$ is the return on the futures contract for period $t$. The sample yielded 1757 daily, 353 weekly, 176 bi-weekly, 84 monthly returns for the 2007-2013 period (in-sample period), and 251 daily returns for 2014 period (out-of-sample period for ex-ante tests). In order to avoid the day of the week anomalies, Wednesday prices are used for the calculation of the weekly and bi-weekly returns.

${ }^{1}$ Source : Futures Industry Association Annual Volume Survey 
For each return interval, seven estimation periods ranging from one year to seven years are examined. One year estimation period covers data only from 2013 observations. Two year period covers data from the beginning of 2012 to the end of 2013; three year period covers data from the beginning of 2011 to the end of 2013. The remaining estimation periods are created in a similar fashion.

For each sample, the following OLS regression model is used to estimate the hedge ratios (betas):

$R_{t}=\alpha+\beta R_{f t}+\epsilon_{t}$

where $R_{t}$ is the return on portfolio in period $\mathrm{t}, R_{\mathrm{ft}}$ is the ISE-30 futures return in period $\mathrm{t}, \alpha$ is the intercept term, $B$ is the hedge ratio, and $\epsilon_{t}$ is the error in period $t$.

Following Daves et.al. (2000), the standard error of the estimated beta, $S_{\beta}$, is defined as follows:

$S_{\beta}=\frac{1}{\sqrt{n-1}} \times \frac{S_{\epsilon}}{S_{f}}$

where, $S_{\epsilon}$ is the standard deviation of the estimated errors in equation (2), $S_{f}$ is the standard deviation of the futures returns, and $n$ is the number of observations in each sample. This measure is used to assess the precision of the estimated betas.

As mentioned in previous section, lengthening the estimation period should improve the precision of the beta estimates. However, if a portfolio constituents' fundamental structure changes over the estimation period, estimated betas might become biased. Therefore, further tests are needed to assess the stability of betas over estimation periods. To test the stability of betas, asset betas are first estimated by using only 2013 daily return data. Then, one additional year of return data is added to the estimation period and the following equation is estimated:

$R_{t}=\alpha+\gamma_{2012} D_{2012}+\beta R_{f t}+\Delta_{2012} D_{2012} R_{f t}+\epsilon_{t}$

Where

$R_{t} \quad$ the return on portfolio in period $\mathrm{t}$

$R_{f t} \quad$ the ISE-30 futures return in period $\mathrm{t}$

$\alpha \quad$ the intercept for portfolio in 2013

b the beta for portfolio in 2013

$\epsilon_{t} \quad$ the error for the period $\mathrm{t}$

$D_{2012} 1$ for observations in 2012, 0 otherwise

$V_{2012}$ the intercept for portfolio in 2012

$\Delta_{2012}$ the shift in beta by adding the 2012 returns to the estimation period. 
If $\Delta_{2012}$ is significantly different from zero, then the beta for 2012-2013 is significantly different from the beta of 2013. Hence it is not stable over 2012-2013 estimation period.

If there is shift in the beta in the 2012-2013 estimation period, an additional test is performed by adding 2011 return data to the estimation period using the following equation:

$R_{t}=\alpha+\gamma_{2012} D_{2012}+\gamma_{2011} D_{2011}+\beta R_{f t}+\Delta_{2011} D_{2011} R_{f t}+\epsilon_{t}$

Now $B$ is the beta for the 2011-2013 period and $\Delta_{2011}$ is the shift in beta by adding the 2011 returns to the estimation period.

Again if $\Delta_{2011}$ is significantly different from zero, returns from the previous year are added to the sample and an equation similar to equation 5 is estimated. The procedure continues until 2007 returns are added to the estimation period.

Hedge ratios calculated are then used examine their ex-ante performance in 2014 period for one month, three month, six month and one year hedge periods. The number of futures contracts to be shorted, $\mathrm{N}_{\mathrm{F}}$, is calculated by the following formula:

$N_{F}=\beta \frac{\text { Portfolio Value at the Beginning of the Hedge }}{\text { ISE30 Futures } \times \text { Index Multiplier }}$

To evaluate the effectiveness of the hedge, we use the following ratio suggested for this purpose by Butterworth and Holmes (2001):

$\frac{\sigma_{U}^{2}-\sigma_{H}^{2}}{\sigma_{U}^{2}}$

Where, $\sigma_{U}{ }^{2}$ is the variance of the unhedged portfolio, and $\sigma_{H}{ }^{2}$. This ratio shows the degree of risk reduction provided by hedging with index futures. The higher the ratio, the more effective the hedge is.

\section{RESULTS}

\subsection{Results on the Effect of Return Interval and Estimation Period}

Using daily, weekly, bi-weekly and monthly returns and estimation periods ranging from one year to seven years, betas are estimated. The beta and $S_{6}$ are calculated for each return interval and estimation period. This procedure yielded 28 betas. Table 2 summarizes the results. 
Table 2: The Effect of Return Interval and Estimation Period

\begin{tabular}{|c|c|c|c|c|c|c|c|c|}
\hline \multirow{2}{*}{$\begin{array}{c}\text { Estimation } \\
\begin{array}{c}\text { Period for } \\
\text { Beta }\end{array}\end{array}$} & \multicolumn{9}{|c|}{ Return Interval } \\
\cline { 2 - 9 } & \multicolumn{2}{|c|}{ Daily } & \multicolumn{2}{c|}{ Weekly } & \multicolumn{2}{c|}{ Bi-weekly } & \multicolumn{2}{c|}{ Monthly } \\
\cline { 2 - 9 } & Beta & $\mathbf{S}_{\boldsymbol{\beta}}$ & Beta & $\mathbf{S}_{\boldsymbol{\beta}}$ & Beta & $\mathbf{S}_{\boldsymbol{\beta}}$ & Beta & $\mathbf{S}_{\boldsymbol{\beta}}$ \\
\hline 2013 & 0.6788 & 0.0365 & 0.6415 & 0.0859 & 0.6938 & 0.0858 & 0.5028 & 0.1736 \\
\hline $2012-2013$ & 0.6051 & 0.0238 & 0.5069 & .0663 & 0.5838 & 0.0648 & 0.3005 & 0.1072 \\
\hline $2011-2013$ & 0.6382 & 0.0225 & 0.5022 & 0.0564 & 0.5004 & 0.0691 & 0.3920 & 0.0874 \\
\hline $2010-2013$ & 0.6729 & 0.0232 & 0.5333 & 0.0583 & 0.5367 & 0.0734 & 0.4205 & 0.1257 \\
\hline $2009-2013$ & 0.6390 & 0.0197 & 0.5496 & 0.0458 & 0.5483 & 0.0630 & 0.4894 & 0.1043 \\
\hline $2008-2013$ & 0.6516 & 0.0159 & 0.5790 & 0.0365 & 0.5689 & 0.0467 & 0.5291 & 0.0826 \\
\hline $2007-2013$ & 0.6473 & 0.0142 & 0.5927 & 0.0319 & 0.5892 & 0.0418 & 0.5392 & 0.0698 \\
\hline
\end{tabular}

Samples with daily returns provided the smallest $S_{B}$. As the return interval increases, the standard error also increases. Based on these findings, it can be concluded that shorter return intervals are associated with smaller standard errors. However, the standard error of the beta does not always decrease as the sample size increases. Although for all return intervals the smallest standard error is provided with the longest estimation period, in certain cases it increases as the estimation period increases. Another interesting finding is that betas tend to decrease as the estimation period increases and they tend to increase as the return interval decreases. As expected, all of the betas are less than unity.

\subsection{Stability Tests}

The first regression to test stability provided a significant shift coefficient. Therefore, we added one more year to the estimation period and reran the regression. This time shift coefficient turned out to be insignificant. This result is in line with the tests of effect of the return interval and estimation period. When 2012 and 2013 daily returns are used for the estimation of the hedge ratio, a smaller standard error than the standard error of the hedge ratio, calculated only from 2013 daily returns, resulted. Results on the stability of beta suggest that in estimating beta, samples with more than two years of return data result in biased estimates. Betas estimated with longer estimation periods fail to capture structural changes that shift betas of the shares in the portfolio.

\subsection{Ex-ante Tests}

The results of the ex-ante tests are summarized in Tables 3. Contrary to the results of the ex-post tests, better variance reduction is provided with increased return interval. In general, as the return interval increases so does the hedge effectiveness. Betas estimated using monthly returns provide the best hedge efficiency over all hedge periods. As was expected, as the hedge period increases, the efficiency of the hedge decreases. However, this reduction is less marked with betas estimated from monthly returns. 
Table 3: Ex-Ante performance of the hedge ratios

\begin{tabular}{|c|c|c|c|c|c|}
\hline \multicolumn{6}{|c|}{ Betas calculated from daily returns } \\
\hline \multirow{2}{*}{$\begin{array}{c}\text { Estimation } \\
\text { Period }\end{array}$} & \multirow[b]{2}{*}{ Beta } & \multicolumn{4}{|c|}{ Hedge Period } \\
\hline & & One Month & Three Month & Six Month & One Year \\
\hline 2013 & 0.6788 & 0.5725 & 0.3975 & 0.3230 & 0.2881 \\
\hline $2012-2013$ & 0.6051 & 0.6252 & 0.4986 & 0.4464 & 0.3797 \\
\hline 2011-2013 & 0.6382 & 0.6169 & 0.4532 & 0.3961 & 0.3429 \\
\hline $2010-2013$ & 0.6729 & 0.5844 & 0.3977 & 0.3344 & 0.2967 \\
\hline $2009-2013$ & 0.6390 & 0.6161 & 0.4519 & 0.3947 & 0.3419 \\
\hline $2008-2013$ & 0.6516 & 0.6051 & 0.4327 & 0.3734 & 0.3260 \\
\hline $2007-2013$ & 0.6473 & 0.6089 & 0.4393 & 0.3807 & 0.3315 \\
\hline \multicolumn{6}{|c|}{ Betas calculated from weekly returns } \\
\hline \multirow{2}{*}{$\begin{array}{l}\text { Estimation } \\
\text { Period }\end{array}$} & \multirow[b]{2}{*}{ Beta } & \multicolumn{4}{|c|}{ Hedge Period } \\
\hline & & One Month & Three Month & Six Month & One Year \\
\hline 2013 & 0.6415 & 0.6100 & 0.4572 & 0.3906 & 0.3388 \\
\hline $2012-2013$ & 0.5069 & 0.6703 & 0.5907 & 0.5484 & 0.4501 \\
\hline $2011-2013$ & 0.5022 & 0.6829 & 0.5935 & 0.5515 & 0.4520 \\
\hline $2010-2013$ & 0.5333 & 0.6764 & 0.5723 & 0.5279 & 0.4368 \\
\hline $2009-2013$ & 0.5496 & 0.6709 & 0.5585 & 0.5127 & 0.4266 \\
\hline $2008-2013$ & 0.5790 & 0.6576 & 0.5294 & 0.4805 & 0.4041 \\
\hline $2007-2013$ & 0.5927 & 0.6498 & 0.5138 & 0.4632 & 0.3918 \\
\hline \multicolumn{6}{|c|}{ Betas calculated from bi-weekly returns } \\
\hline \multirow{2}{*}{$\begin{array}{c}\text { Estimation } \\
\text { Period }\end{array}$} & \multirow[b]{2}{*}{ Beta } & \multicolumn{4}{|c|}{ Hedge Period } \\
\hline & & One Month & Three Month & Six Month & One Year \\
\hline 2013 & 0.6938 & 0.5553 & 0.3711 & 0.2930 & 0.2653 \\
\hline $2012-2013$ & 0.5838 & 0.6394 & 0.5240 & 0.4746 & 0.3999 \\
\hline 2011-2013 & 0.5004 & 0.6832 & 0.5946 & 0.5527 & 0.4528 \\
\hline $2010-2013$ & 0.5367 & 0.6754 & 0.5696 & 0.5249 & 0.4348 \\
\hline $2009-2013$ & 0.5483 & 0.6714 & 0.5597 & 0.5140 & 0.4274 \\
\hline $2008-2013$ & 0.5689 & 0.6626 & 0.5400 & 0.4922 & 0.4124 \\
\hline $2007-2013$ & 0.5892 & 0.6519 & 0.5179 & 0.4678 & 0.3951 \\
\hline \multicolumn{6}{|c|}{ Betas calculated from monthly returns } \\
\hline \multirow{2}{*}{$\begin{array}{l}\text { Estimation } \\
\text { Period }\end{array}$} & \multirow[b]{2}{*}{ Beta } & \multicolumn{4}{|c|}{ Hedge Period } \\
\hline & & One Month & Three Month & Six Month & One Year \\
\hline 2013 & 0.5028 & 0.6822 & 0.5987 & 0.5511 & 0.4518 \\
\hline $2012-2013$ & 0.3005 & 0.5953 & 0.5715 & 0.5378 & 0.4211 \\
\hline 2011-2013 & 0.3920 & 0.6650 & 0.6161 & 0.5795 & 0.4621 \\
\hline $2010-2013$ & 0.4205 & 0.6758 & 0.6182 & 0.5805 & 0.4659 \\
\hline $2009-2013$ & 0.4894 & 0.6841 & 0.6004 & 0.5592 & 0.4567 \\
\hline $2008-2013$ & 0.5291 & 0.6776 & 0.5755 & 0.5315 & 0.4392 \\
\hline $2007-2013$ & 0.5392 & 0.6746 & 0.5675 & 0.5226 & 0.4333 \\
\hline
\end{tabular}


Results on the stability of beta suggest that in estimating beta, samples with more than two years of return data result in biased estimates. According to the stability test results betas estimated with longer estimation periods fail to capture structural changes that shift portfolio constituents' betas. The results on the ex-ante hedge effectiveness suggest just the opposite of ex-post stability results. The ex-ante hedging results show that the hedge effectiveness is positively related with the estimation period, it generally increases as the estimation period increases. However, an estimation period longer than five years results in decreased hedge efficiency for betas estimated from all return intervals. These results show the importance of employing ex-ante tests on studies on hedge effectiveness. The results suggest that drawing conclusions based ex-post results might be misleading.

\section{CONCLUSION}

This study analyses the hedging effectives of ISE-30 Stock Index Futures on an actual diversified portfolio of 15 stocks for the period between January 2007 and December 2014. The study focusses on the selection of the appropriate return interval and the estimation period that should be employed in the estimation of optimal hedge ratio. We calculate the hedge ratios and their standard errors using daily, weekly, bi-weekly and month returns with one to seven year samples for the period between January 2007 and December 2013. We then apply the calculated beta for the implementation of hedge strategies in 2014.

Ex-post results suggest that employing daily returns for the estimation of betas results in the greatest precision. The results suggest the same for estimation period. Ex-post stability tests suggest that daily returns from a two year estimation period should be used for the calculation of hedge ratios. However, ex-ante performance of betas calculated with high return intervals and small estimation periods are disappointing. Ex-ante tests show that highest reduction in variance through hedge is provided by hedge ratios calculated on long return intervals. Moreover, the efficiency increases as the length of the estimation period increases. However, estimation periods longer than five years do not provide good hedge efficiency.

To sum, it can be concluded that both the return measurement interval and the length of the estimation period have an important impact on beta estimation. According to the results of this study using monthly returns provides the best hedge efficiency. Hedge efficiency decreases as the hedge period decreases. Therefore, it can be concluded that the best hedging effectiveness can be achieved if hedge portfolios are re-balanced monthly with (rolling) betas that are re-estimated every month with new return data.

It should be noted that the results should be interpreted with care given the limitations of this study. We use only one portfolio for testing the hedge effectiveness and have only one year hold-out period. In future work we intend to use many portfolios with differing risk levels and the hedge efficiency will be tested on a variety of hold-out periods. In future work we also intend to analyse these effects through factor models and compare the results with results of GARCH based models. The effects of thin trading, which are a common feature of emerging markets, will also be taken into consideration in future work using more sophisticated methods than the one we use in this study. 


\section{REFERENCES}

- Altman, E. I., B. Jacquillat and M. Levasseur, 1974, "Comparative Analysis of Risk Measures: France and the United States," Journal of Finance 29, 1495-1511.

- Baesel, J. B.,1974, “On the Assesment of Risk: Some Further Considerations," The Journal of Finance 29, 1491-1494.

- Bhaduri, S.N. and S.R.S. Durai, 2008, "Optimal hedge ratio and hedging effectiveness of stock index futures: evidence from India," Macroeconomics and Finance in Emerging Market Economies 1(1), 121-134.

- Blume, M. E., 1971, “On the Assessment of Risk," Journal of Finance, 1-10.

- Blume, M., 1975, "Betas and Their Regression Tendencies," Journal of Finance 30, 785-795.

- Bos, T. and Newbold, P., 1984, "An empirical investigation of the possibility of stochastic systematic risk in the market model," Journal of Business, 7, 35-41.

- Brooks, R.D., Faff, R.W. and Lee, J.H.H., 1992, "The form of time variation of systematic risk: Some Australian evidence," Applied Financial Economics, 2, 19198.

- Bowman, C., 2004, "Cross-hedging effectiveness in emerging markets experiencing structural change" Working paper, Australia National University.

Retrieved from www.ssrn.com

- Brooks, R.D., R.W. Faff, and J.H.H. Lee,1994, "Beta stability and portfolio formation," Pacific Basin Finance Journal 2, 463-79.

- Butterworth, D. and P. Holmes, 2001, "The hedging effectiveness of stock index futures: evidence for the FTSE-100 and FTSE-Mid250 indexes traded in the UK," Applied Financial Economics 11(1), 57-68.

- Cohen, K., S. Maier, R. Schwartz, and D. Witcomb, 1985, The Microstructure of Securities Markets. Prentice Hall.

- Collins, D.W., J. Ledolter, and J. Rayburn, 1987, "Some further evidence on the stochastic properties of systematic risk," Journal of Business 60, 425-48.

- Çinko, E. and M. Avcl, 2010, "The hedge period length and the hedging effectiveness: An application on TURKDEX-ISE 30 Index Futures Contracts," Journal of Yaşar University 5(18), 3081-3090.

- Daves, P. R., M. C. Ehrhardt, and R. A. Kunkel, 2000, "Estimating systematic risk: the choice of return interval and estimation period," Journal of Financial and Strategic Decisions 13(1), 7-13.

- Er, H., \& A. Hushmat, 2012, "The Impact of the Leverage Provided by the Futures on the Performance of Technical Indicators: Evidence from Turkey," International Journal of Economics and Finance Studies 4(2), .

- $\quad$ Faff, R.W. and R.D. Brooks, 1996, "Further evidence on the relationship between beta stability and the length of the length of estimation period," Advances in Investment Analysis and Portfolio Management

- $\quad$ Figlewski, S., 1984, "Hedging performance and basis risk in stock index futures," The Journal of Finance 39(3), 657-669.

- Floros, C., and D. Vougas, 2006, "Hedging effectiveness in Greek stock index futures market, 1999-2001." International Research Journal of Finance and 
Economics 5, 7-18.

- Frank J. F, and J.C. Francis, 1978, "Beta as a Random Coefficient," Journal of Financial and Quantitative Analysis 13, 101-116.

- Handa, P., Kothari, S. P., \& Wasley, C. (1989). The relation between the return interval and betas: Implications for the size effect. Journal of Financial Economics, 23(1), 79-100.

- Holmes, P., 1996, "Stock index futures hedging: hedge ratio estimation, duration effects, expiration effects and hedge ratio stability," Journal of Business Finance \& Accounting 23(1), 63-77.

- Howard, C. T., \& , L. J. D'Antonio, 1984, “A risk-return measure of hedging effectiveness," Journal of Financial and Quantitative Analysis 19(01), 101-112.

- Kavussanos, M.G., and I.D. Visvikis, 2008, "Hedging effectiveness of the Athens stock index futures contracts." European Journal of Finance, 14(3), 243-270.

- Kim, D., 1999, "Sensitivity of Systematic Risk Estimates to the Return Measurement Interval under Serial Correlation," Review of Quantitative Finance and Accounting 12, 49-64

- Lien, D., 1996, "The effect of the cointegration relationship on futures hedging: A note," Journal of Futures Markets 16, 773-780.

- Lindahl, M., 1992, "Minimum variance hedge ratios for stock index futures: duration and expiration effects" Journal of Futures Markets 12(1), 33-53.

- Moosa, I., 2003, "The sensitivity of optimal hedge ratio to model specification." Financial Letters 1, 15-20.

- Olgun, O., \& I. H. Yetkiner, 2011, "Determination of Optimal Hedging Strategy for Index Futures: Evidence from Turkey," Emerging Markets Finance and Trade 47(6), 68-79.

- Roenfeldt, R., 1978, "Further Evidence on the Stationarity of Beta Coefficients," Journal of Financial and Quantitative Analysis March, 11-21.

- Sim, A.B., and R. Zurbruegg, 2001, "Dynamic hedging effectiveness in South Korean index futures and the impact of the Asian financial crisis," Asia-Pacific Financial Markets 8(3), 237-258.

- Sunder, S., 1980, "Stationarity of market risk: Random coefficients tests for individual stocks." Journal of Finance, 883-896. 